3 de Gracia J, Vendrell M, Álvarez A, et al. Immunoglobulin therapy to control lung damage in patients with common variable immunodeficiency. Int Immunopharmacol 2004; 6: 745-753.

4 de Gracia J, Morell F, Bofill JM, Rodrigo MJ, Cosculluela C. Impaired lung function in patients with $\operatorname{IgA}$ deficiency and low levels of IgG2 or IgG3. N Engl J Med 1986; 314: 925-926.

5 de Gracia J, Miravitlles $M$, Vendrell $M$, Rodrigo MJ, Codina R, Morell F. Study of the IgG subclasses in symptomatic patients with IgA deficiency. Med Clin (Barc) 1995; 104: 728-731.

6 Rodrigo MJ, Vendrell M, Cruz MJ, et al. Utility of the antibody response to a conjugated $H$. influenzae type $\mathrm{B}$ vaccine for diagnosis of primary humoral immunodeficiency. Am J Respir Crit Care Med 2000; 162: 1462-1465.

7 Rodrigo MJ, Miravitlles M, Cruz MJ, et al. Characterization of specific immunoglobulin G (IgG) and its subclasses (IgG1 and IgG2) against the 23-valent pneumococcal vaccine in a healthy adult population: proposal for response criteria. Clin Diagn Lab Immunol 1997; 4: 168-172.

8 Vendrell M, de Gracia J, Rodrigo MJ, et al. Antibody production deficiency with normal IgG levels in bronchiectasis of unknown etiology. Chest 2005; 127: 197-204.

9 Ambrosino DM, Siber GR, Chilmonczyk BA, Jernberg JB, Finberg RW. An immunodeficiency characterized by impaired antibody responses to polysaccharides. $N$ Engl J Med 1987; 316: 790-793.

10 de Gracia J, Rodrigo MJ, Morell F, et al. IgG subclass deficiencies associated with bronchiectasis. Am J Respir Crit Care Med 1996; 153: 650-655.

11 Miravitlles M, de Gracia J, Rodrigo MJ, et al. Specific antibody response against the 23-valent pneumococcal vaccine in patients with $\alpha_{1}$-antitrypsin deficiency with and without bronchiectasis. Chest 1999; 116: 946-952.

\title{
Combination therapy with bosentan and phosphodiesterase-5 inhibitor in pulmonary arterial hypertension
}

\section{To the Editors:}

HOEPER et al. [1] have produced an interesting report of their clinical experience of combined therapy with bosentan and sildenafil in patients with idiopathic pulmonary arterial hypertension. Whilst it is true that the relatively scant literature supporting the use of phosphodiesterase- 5 inhibitors is centred around sildenafil, its relatively short duration of action requires the use of a thrice-daily regime. This has significant implications for compliance and, since treatment is continual, has large implications in the cost of treatment. It would be more logical to use a long-acting phosphodiesterase-5 inhibitor, and, with the advent of tadalafil, once-daily treatment becomes possible.

Here, we report our experience with a combination of bosentan and tadalafil in a 42-yr-old male with idiopathic pulmonary hypertension who had documented poor compliance with nebulised iloprost. Sildenafil $25 \mathrm{mg}$ t.d.s. was added to bosentan, following a clinical deterioration and the finding of an estimated pulmonary artery systolic pressure of $130 \mathrm{mmHg}$, and this caused a fall in pulmonary artery pressure to $50 \mathrm{mmHg}$. Treatment with sildenafil was stopped 1 month later at another centre, and the pulmonary artery systolic pressure increased to $100 \mathrm{mmHg}$. Subsequently, sildenafil was restarted in combination with bosentan, and exercise tolerance doubled. After 3 months of combination treatment, the issue of compliance was raised by the patient and it was decided to substitute tadalafil $20 \mathrm{mg}$ once daily for the sildenafil. The patient has continued on tadalafil for 9 months with an excellent symptomatic response. The last estimated pulmonary artery pressure was $61 \mathrm{mmHg}$.

\section{A.H. Morice, S. Mulrennan and A. Clark}

Division of Academic Medicine, University of Hull, Castle Hill Hospital, Hull, UK.

\section{REFERENCE}

1 Hoeper MM, Faulenbach C, Golpon H, Winkler J, Welte T, Niedermeyer J. Combination therapy with bosentan and sildenafil in idiopathic pulmonary arterial hypertension. Eur Respir J 2004; 24: 1007-1010.

DOI: 10.1183/09031936.05.00030405

\section{From the authors:}

I am grateful for the comments by A.H. Morice and coworkers, although their case report leaves several questions unanswered. More information than just the systolic pulmonary artery pressure is needed to appraise the haemodynamic response to tadalafil. One wonders whether this patient ever underwent pulmonary vasoreactivity testing. With such a 